\title{
Analisis Pengendalian Kualitas dengan Menggunakan First Pass Yield dan Fishbone Diagram pada PT X
}

\author{
Sri Susilawati Islam ${ }^{1 *}$, Fatkhurozak ${ }^{2}$ \\ ${ }^{1)}$ Universitas Sampoerna \\ ${ }^{2)}$ Universitas Borobudur \\ *sri.islam@sampoernauniversity.ac.id
}

\begin{abstract}
Industrial competition in the current global industrial era is not only influenced by product prices but also influenced by customer satisfaction with the products, one of the factors that influence customer satisfaction is the quality of the products, for which quality control is needed. This studies aims to measure the level of quality control as seen from the percentage of defective products and customer satisfaction. This research was conducted at PT. X which is a cable producing company. The method used in this studies is the First Pass Yield to measure the percentage of defective products, Customer Complaints and production claims related to the quality of raw materials \& haspels to measure customer satisfaction through questionnaires. From data processing, the average value of First Pass Yield is $94.2 \%$ which indicates the average rate of defective products per month is 5.8\%. Customer complaints show customers are not satisfied with the Non Standard Length relating to the marker and cable length. So as to improve product competitiveness we provide several improvement proposals based on the fault categories that arise.
\end{abstract}

Keywords : quality control, first pass yield, customer satisfaction

\begin{abstract}
Abstrak
Persaingan industri di era industri global saat ini bukan hanya dipengaruhi oleh harga produk saja tetapi juga dipengaruhi oleh kepuasan pelanggan terhadap produk yang dihasilkan, salah satu faktor yang mempengaruhi kepuasan pelanggan adalah kualitas dari produk yang dihasilkan, untuk itu diperlukan adanya pengendalian kualitas. Penelitian ini bertujuan untuk mengukur tingkat pengendalian kualitas yang dilihat dari jumlah persentase produk cacat dan kepuasan pelanggan. Penelitian ini dilakukan pada perusahaan PT. X yang merupakan perusahaan penghasil kabel. Metode yang digunakan pada penelitian ini adalah First Pass Yield untuk mengukur persentase produk cacat, Customer Complaint dan Klaim produksi berkaitan dengan kualitas bahan baku \& haspel untuk mengukur kepuasan pelanggan melalui kuisioner. Dari pengolahan data diperoleh rata-rata nilai First Pass Yield adalah $94.2 \%$ yang menandakan rata-rata tingkat produk cacat tiap bulannya sebesar 5.8\%. Customer complaint menunjukkan pelanggan belum puas terhadap Non Standar Length yang berkaitan dengan penanda dan panjang kabel. Sehingga untuk meningkatkan daya saing produk kami memberikan beberapa usulan perbaikan berdasarkan kategori kesalahan yang timbul.
\end{abstract}

Kata kunci : pengendalian kualitas, first pass yield, kepuasan pelanggan

\section{Pendahuluan}

Di era persaingan industri yang sangat kompetitif saat ini pelaku bisnis melakukan berbagai cara untuk memenangkan persaingan pasar, dimana kompetisi bisnis sangat ditentukan oleh customer value yang bukan hanya dipengaruhi oleh harga tetapi juga kualitas dari produk maupun jasa yang dihasilkan. Hal ini dapat dilihat dari berbagai industri yang melakukan upaya peningkatan 
kualitas, baik dengan cara peningkatan kualitas SDM maupun peningkatan teknologi fasilitas yang dapat mendukung terciptanya peningkatan kualitas produk maupun jasa yang mereka hasilkan. Feigenbaum menyatakan bahwa kualitas merupakan keseluruhan karakteristik dari suatu produk maupun jasa yang mampu memberikan kepuasan kepada pelanggan atau konsumen [2]. Maka dari itu peranan kualitas produk sangat penting dalam situasi pemasaran yang semakin bersaing, karena dapat mempengaruhi maju atau tidaknya perusahaan.

Salah satu aktifitas dalam menciptakan kualitas agar sesuai standar adalah dengan menerapkan sistem pengendalian kualitas yang tepat, mempunyai tujuan dan tahapan yang jelas, serta memberikan inovasi dalam pencegahan dan penyelesaian masalahmasalah yang dihadapi perusahaan [3]. Penelitian ini berfokus pada analisis dan evaluasi pengendalian kualitas yang telah dilakukan oleh perusahaan manufaktur, dari hasil evaluasi akan dilakukan perbaikan berdasarkan kategori kesalahan yang timbul. Perbaikan tersebut bertujuan agar perusahaan dapat melakukan continue improvement sehingga daya saing perusahaan juga meningkat.

Penelitian ini dilakukan di perusahaan manufaktur penghasil kabel, data yang akan diolah merupakan data yang diambil selama satu tahun pada tahun 2016.

\subsection{Pengendalian Kualitas}

Pengendalian kualitas merupakan alat bagi manajemen untuk memperbaiki kualitas produk bila diperlukan, mempertahankan kualitas produk yang sudah tinggi dan mengurangi jumlah produk yang rusak.

Ada beberapa pengertian pengendalian kualitas :

1. Pengendalian kualitas adalah suatu aktifitas untuk menjaga dan mengarahkan agar kualitas produk perusahaan dapat dipertahankan sebagaimana telah direncanakan [1].

2. Pengendalian kualitas adalah merencanakan dan melaksanakan cara yang paling ekonomis untuk membuat sebuah barang yang akan bermanfaat dan memuaskan tuntutan konsumen secara maksimal [4].

3. Pengendalian kualitas merupakan alat penting bagi manajemen untuk memperbaiki kualitas produk bila diperlukan, mempertahankan kualitas yang sudah tinggi dan mengurangi jumlah barang yang rusak [5].

Dapat disimpulkan bahwa pengendalian kualitas adalah aktifitas untuk menjaga, mengarahkan, mempertahankan dan memuaskan tuntutan konsumen secara maksimal.

\subsection{Faktor-Faktor Mendasar yang Mempengaruhi Kualitas}

Kualitas produk secara langsung dipengaruhi oleh 9 bidang atau 9M. Pada masa sekarang ini industri disetiap bidang bergantung pada sejumlah besar kondisi yang membebani produksi melalui suatu cara yang tidak pernah dialami periode sebelumnya [2].

1. Market (Pasar)

Jumlah produk baru dan baik ditawarkan dipasar terus bertumbuh pada laju yang eksplosif. Konsumen diarahkan untuk mempercayai bahwa ada sebuah produk yang dapat memenuhi hampir setiap kebutuhan. Pada masa sekarang konsumen meminta dan memperoleh produk yang lebih baik untuk memenuhi kebutuhan ini. Pasar menjadi lebih besar ruang lingkupnya dan secara fungsional lebih terspesialisasi di dalam produk yang ditawarkan. Dengan bertambahnya perusahaan, pasar menjadi bersifat internasional dan mendunia. Akhirnya bisnis harus lebih fleksibel dan mampu merubah arah dengan cepat.

2. Money (Uang)

Meningkatnya persaingan dalam banyak bidang bersamaan dengan fluktuasi ekonomi dunia telah menurunkan margin laba. Pada waktu yang bersamaan, kebutuhan akan otomasi dan mekanisme mendorong pengeluaran biaya yang besar untuk biaya proses dan perlengkapan baru. 
Penambahan investasi pabrik, harus di bayar dengan naiknya produktivitas, yang dapat menimbulkan kerugian yang besar pada saat memproduksi dalam jumlah banyak, disebabkan oleh banyaknya produk yang cacat dan dapat mengulang pekerjaan yang cukup serius. Kenyataan ini memfokuskan perhatian pada manajer bahwa biaya kualitas sebagai salah satu dari titik lunak tempat biaya operasi dan kerugian dapat diturunkan untuk memperbaiki laba.

3. Management (manajemen)

Tanggung jawab kualitas harus di didistribusikan oleh beberapa bagian khusus. Bagian pemasaran melalui fungsi perencanaan produknya, harus membuat persyaratan produk. Bagian perancangan bertanggung jawab merancang produk dengan dengan spesifikasinya. Bagian produksi mengembangkan dan memperbaiki proses untuk memberikan kemampuan yang baik dalam membuat produk sesuai dengan spesifikasi rancanganya. Bagian pengendalian kualitas merencanakan pengukuran kualitas pada seluruh aliran proses yang menjamin bahwa hasil akhir memenuhi persyaratan kualitas dan kualitas pelayanan, setelah produk sampai pada konsumen menjadi bagian yang penting dan bagian produk total. Hal ini yang telah menambah beban manajemen puncak, khususnya bertambahnya kesulitan dalam mengalokasikan tanggung jawab yang tepat untuk mengoreksi penyimpangan dari standart kualitas.

\section{Motivation (motivasi)}

Penelitian tentang motivasi manusia menunjukkan bahwa uang adalah sebagai hadiah tambahan, para pekerja pada sekarang ini memerlukan sesuatu yang memperkuat rasa keberhasilan didalam pekerjaan mereka dan pengakuan bahwa mereka secara pribadi memerlukan tambahan atas tercapainya tujuan perusahaan. Hal ini membimbing kearah kebutuhan yang tidak ada sebelumnya yaitu pendidikan kualitas dan komunikasi yang lebih baik tentang kesadaran kualitas.

5. Men (manusia)

Pertumbuhan yang cepat dalam pengetahuan teknis dan penciptaan seluruh bidang baru seperti elektronika komputer menciptakan suatu permintaan yang besar akan pekerjaan dengan pengetahuan khusus. Pada waktu yang sama situasi ini menciptakan permintaan akan ahli teknik sistem yang akan mengajak semua bidang spesialisasi untuk bersama merencanakan, menciptakan dan mengoperasikan berbagai sistem yang akan menjamin suatu hasil yang diinginkan.

6. Material (bahan)

Disebabkan oleh biaya produksi dan standar kualitas, para teknisi memilih bahan dengan batasan yang lebih ketat dari pada sebelumnya. Akibatnya spesifikasi bahan menjadi lebih ketat dan keanekaragaman menjadi lebih besar.

7. Machine And Mecanization (Mesin Dan Mekanisme)

Permintaan perusahaan untuk mencapai penurunan biaya dan volume produksi untuk kepuasan pelanggan telah mendorong penggunaan perlengkapan pabrik yang menjadi lebih rumit dan tergantung pada kualitas bahan yang dimasukkan kedalam mesin tersebut. Kualitas yang baik menjadi faktor yang kritis dalam memelihara waktu kerja mesin agar fasilitasnya dapat digunakan sepenuhnya.

8. Modern Information Metode (Metode Informasi Modern)

Evolusi teknologi komputer membuka kemungkinan untuk mengumpulkan, menyimpan, mengambil kembali, memanipulasi informasi pada skala yang tidak terbayangkan sebelumnya. Teknologi informasi yang baru ini menyediakan cara untuk mengendalikan produk bahkan setelah produk kekonsumen. Metode pemprosesan data yang baru dan konstan memberikan kemampuan untuk mengatur informasi 
yang bermanfaat, akurat, tepatwaktu dan bersifat ramalan mendasari keputusan yang membimbing masa depan bisnis.

9. Mouting Product Requirement (Persyaratan Proses Produksi)

Kemajuan yang pesat dalam perancangan produk, memerlukan pengendalian yang lebih ketat pada seluruh proses pembuatan produk. Meningkatnya persyaratan prestasi yang leih tinggi bagi produk menekankan pentingnya keamanan dan keandalan produk.

\subsection{Dimensi Kualitas}

Ada8 dimensikualitas yang dikembangkan Garvin pada tahun 1987 dan dapat digunakan sebagai kerangka perencanaan strategis dan analisis terutama untuk produk manufaktur. Dimensi tersebut adalah:

1. Kinerja: Karakteristik dari produk inti.

2. Ciri-ciri atau keistimewaan tambahan: Karakteristik sekunder atau pelengkap.

3. Kehandalan: Kemungkinan kecil akan mengalami kerusakan atau gagal dipakai.

4. Kesesuaiandenganspesifikasi: Sejauh mana karakteristik desain dan operasi memenuhi standar yang telah di tetapkan sebelumnya.

5. Dayatahan: Berkaitan dengan berapa lama produk tersebut dapat digunakan.

6. Service ability: Meliputi kecepatan, kompetensi, kenyamanan, mudah direparasi, penanganan keluhan yang memuaskan.

7. Estetika: Daya tarik produk terhadap panca indra.

8. Kualitas yang dipersepsikan : Citra dan reputasi produk serta tanggung jawab perusahaan terhadapnya.

\section{Metoda Penelitian}

Metoda penelitian menjelaskan tentang langkah-langkah yang dilakukan untuk melaksanakan sebuah penelitian. Penelitian ini menggunakan metode kuantitatif dengan melakukan studi pendahuluan berupa deskripsi sitem nyata dan studi literature. Penelitian ini juga bersifat aplikatif terhadap rumus yang ada yang telah disesuaikan dengan kondisi di lapangan, berikut merupakan tahapan dari penelitian ini.

\subsection{Diagram Alir Peneitian}

Metoda yang dipakai dalam penelitian ini berupa langkah kerja serta rangkaian kegiatan dapat dilihat pada Gambar 1.

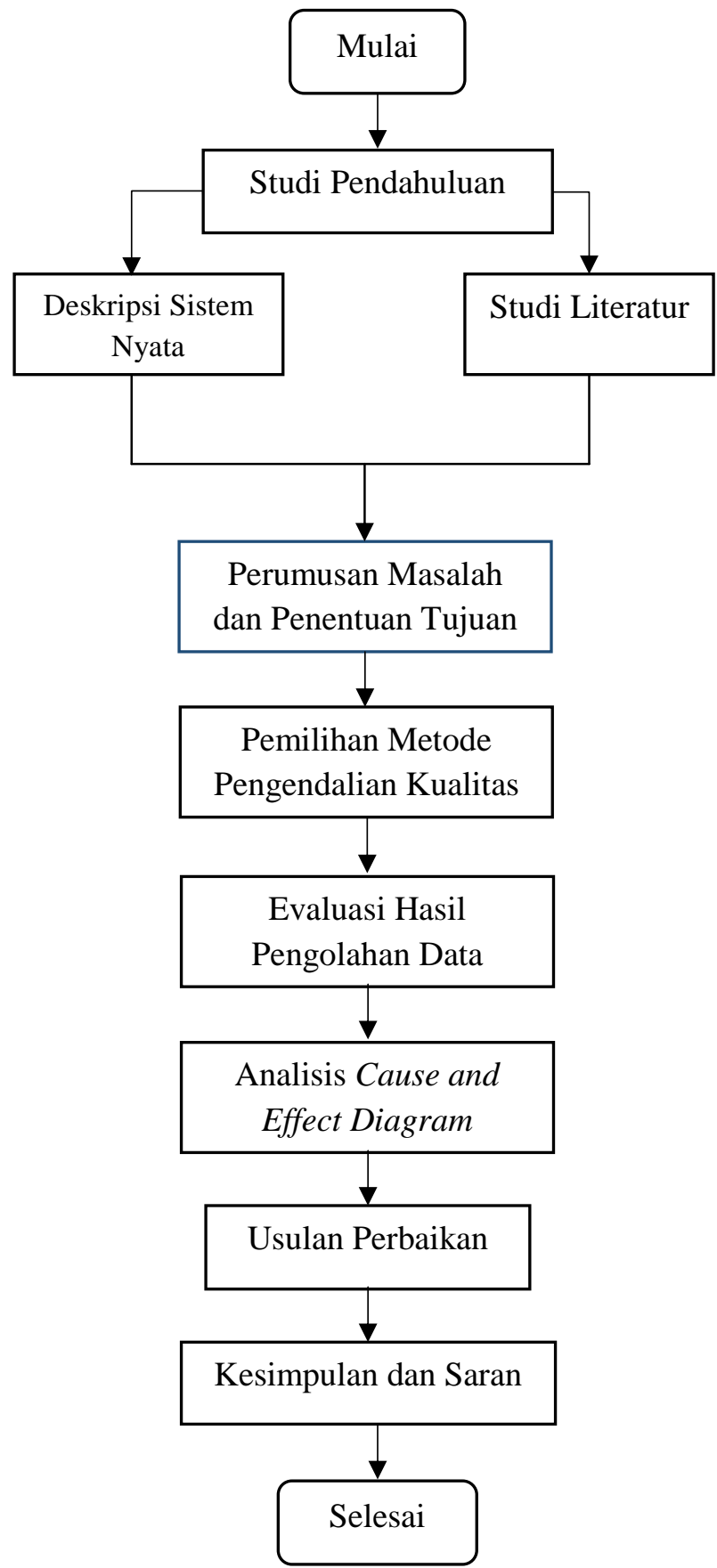

Gambar 1. Diagram Alir Penelitian

1. Studi Pendahuluan

Studi pendahuluan dilakukan dengan melakukan deskripsi sistem nyata dan studi literatur. Deskripsi sistem nyata 
dilakukan dengan melakukan observasi secara langsung ke PT X. Tujuan dari observasi ini untuk mengetahui gambaran sistem riil perusahaan serta mengidentifikasi permasalahan permasalahan yang terjadi. Studi literatur dilakukan untuk mengetahui penelitianpenelitian sebelumnya tentang pengendalian kualitas dan metode yang pernah digunakan.

2. Perumusan Masalah dan PenentuanTujuan

Berdasarkan hasil studi literatur, pada tahap ini dirumuskan masalah yang akan diangkat pada penelitian. Rumusan masalah disusun menjadi satu atau beberapa pertanyaan penelitian yang berguna sebagai acuan utama dalam penelitian. Sementara itu, tujuan penelitian ditetapkan untuk membantu peneliti dalam menjawab pertanyaan penelitian yang telah disusun sebelumnya. Perumusan masalah dan penetapan tujuan yang baik akan membuat masalah menjadi terstruktur dengan batasan-batasan yang jelas.

3. Pemilihan Metode Pengendalian Kualitas

Pada tahap ini dilakukan pemilihan motode pemecahan masalah yang sesuai dari studi literatur yang sudah dilakukan. Pemilihan metode pemecahan masalah berdasarkan permasalahan yang dihadapi pada deskripsi sistem riil yang telah dilakukan pada studi pendahuluan.

4. Evaluasi Hasil Pengolahan Data

Setelah menentukan metode pemecahan masalah kemudian dilakukan pengolahan data, hasil dari pengolahan data kemudian dievaluasi untuk mengetahui faktor yang mempengaruhi kualitas produk.

\section{Analisis Cause and Effect Diagram}

Digunakan untuk mengetahui akar penyebab masalah untuk produk cacat.

Tabel 1. Analisis Cause and Effect Diagram

\begin{tabular}{|c|c|c|c|}
\hline Bulan & $\begin{array}{c}\text { Target } \\
(\text { Min. \%) }\end{array}$ & $\begin{array}{c}\text { Pencapaian } \\
(\%)\end{array}$ & Penjelasan \\
\hline Jan & 99 & 94.4 & $V R C$ \\
\hline $\mathrm{Feb}$ & 99 & 96.0 & $V R C$ \\
\hline Mar & 99 & 97.1 & $V R C$ \\
\hline Apr & 99 & 96.0 & $V R C$ \\
\hline Mei & 99 & 97.1 & $V R C$ \\
\hline Jun & 99 & 96.4 & $V R C$ \\
\hline Jul & 99 & 90.3 & VRC \\
\hline Ags & 99 & 93.7 & $V R C$ \\
\hline Sep & 99 & 81.8 & $V R C$ \\
\hline Okt & 99 & 93.3 & $V R C$ \\
\hline Nov & 99 & 97.4 & $V R C$ \\
\hline Des & 99 & 97.2 & $V R C$ \\
\hline Rata-rata & 99 & 94.2 & \\
\hline
\end{tabular}

6. Usulan Perbaikan

Usulan perbaikan diberikan berdasarkan akar permasalahan yang ditemukan.

7. Kesimpulan dan Saran

Tahap akhir penelitian ini adalah pengambilan kesimpulan berdasarkan analisis sebagai jawaban atas tujuan penelitian yang telah ditetapkan. Pada bagian ini juga dipaparkan saran untuk penelitian berikutnya.

\section{Hasil Penelitian}

\subsection{Pengumpulan dan Pengolahan Data}

Pengumpulan data pada setiap bagian dilakukan dalam satu minggu, data yang dikumpulkan adalah antara lain data First Pass Yield (FPY) dari bagian Final Test, data Customer Complaint dari bagian marketing, data klaim produksi mengenai kualitas bahan baku dan haspel, data pengendalian stabilitas dimensi dan elektris utama mengenai nilai deviasi conductor resistance, nilai deviasi outher sheat diameter dan nilai hot set.

Tabel 2. Key Performance Measurement FPY

\begin{tabular}{lcc}
\hline Bulan & $\begin{array}{c}\text { Total Masalah } \\
\text { (lot) }\end{array}$ & $\begin{array}{c}\text { Output Produksi } \\
\text { (Lot) }\end{array}$ \\
\hline Januari & 4 & $\mathbf{7 1}$ \\
Februari & 3 & 75
\end{tabular}




\begin{tabular}{lcc} 
Maret & 2 & 68 \\
April & 3 & 75 \\
Mei & 1 & 35 \\
Juni & 1 & 28 \\
Juli & 3 & 31 \\
Agustus & 2 & 32 \\
September & 4 & 22 \\
Oktober & 2 & 30 \\
November & 1 & 39 \\
Desember & 3 & 36 \\
\hline Total & 27 & 524 \\
\hline
\end{tabular}

\subsection{First Pass Yield}

First Pass Yield dapat disebut juga persentase kabel tanpa cacat dibanding dengan jumlah output produksi.

$$
\frac{\text { Jumlah Produk Cacat }}{\text { Total Produks! (Output) }} \times 100 \%
$$

Pencapaian FPY pada setiap bulan pada tahun 2016 tidak pernah mencapai target yang telah ditentukan, pencapaian yang tertinggi yaitu pada bulan November sebesar 97.4\% . Rata-rata pencapaian juga hanya mencapai 94.2\% hal ini tentu jadi perhatian untuk dilakukan evaluasi agar dapat dilakukan perbaikan pada fault categories yang paling banyak.

\subsection{Customer Complaint}

Pada tahun 2014- 2016 telah dilakukan questioner terhadap 200 perusahaan pelanggan atau kurang lebih 500 orang.

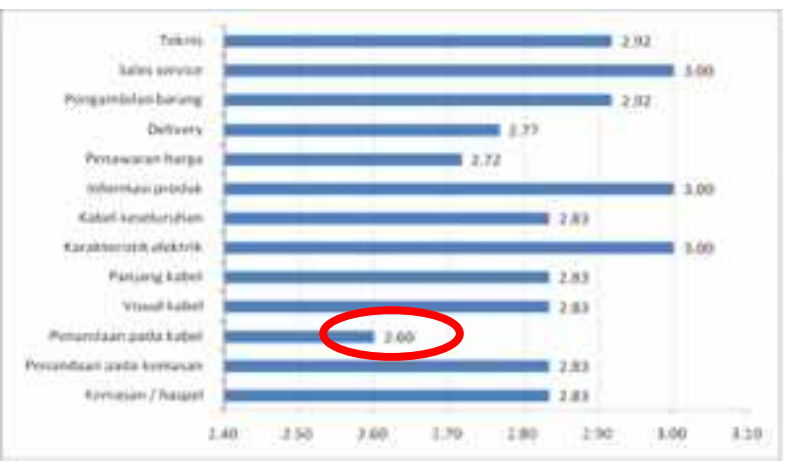

Gambar 2. Grafik evaluasi kepuasan pelanggan Tahun 2014-2016

Ada 13 parameter untuk penilaian melalui questioner tentang kualitas produk kepada pelanggan, rating parameter terendah ada pada parameter penandaan pada kabel. Hal ini berbanding searah dengan data customer complaint yang menunjukan bahwa customer banyak yang complaint terhadap Non standar Length (diperlihatkan pada tabel 3) hal tersebut terkait dengan penandaan kabel dan panjang kabel.

Tabel 3. Data NCR customer complaint sesuai dengan klaim kerusakan

\begin{tabular}{lcccc}
\multicolumn{5}{c}{ Klaim kerusakan } \\
\cline { 2 - 4 } Bulan & $\begin{array}{c}\text { NCR } \\
\text { Konstrual \& }\end{array}$ & $\begin{array}{c}\text { Karakteristik } \\
\text { Elektris }\end{array}$ & $\begin{array}{c}\text { Non } \\
\text { Standart } \\
\text { Length }\end{array}$ & Other \\
\hline Jan & 2 & & 1 & \\
Feb & & & 5 & \\
Mar & & 1 & 1 & 1 \\
Apr & 1 & & 1 & \\
Mei & 1 & & & \\
Jun & 1 & & 2 & \\
Jul & & & & \\
Ags & & 1 & 10 & 1 \\
Sep & 2 & 3 & \\
Okt & & & & \\
Nov & & & & \\
Des & & & & \\
\hline Jumlah & 6 & & & \\
\hline
\end{tabular}

Dengan melihat keterangan dari customer complaint, dari seluruh jumlah klaim pada tahun 2016, NCR untuk Non Standart Lengthmemiliki jumlah komplain paling banyak dalam setahun yaitu 10 kali. Hal ini menunjukan banyaknya kesalahan atau kegagalan produksi pada penandaan jenis kabel dan penandaan panjang kabel.

Jumlah keseluruhan customer complaint dalam setahun (tabel 4) telah melebihi batas maksimum pencapaian pada sasaran terpadu yang telah ditentukan oleh manajemen. Data diatas menunjukan bahwa customer complaint dalam satu tahun tidak mencapai target yaitu maksimal 6 kali dalam setahun, sedangkan pencapaian pada tahun 2016 mencapai 20 kali customer complaint, nilai ini menunjukan banyaknya produk gagal yang lolos uji final test. Maka hal ini perlu untuk dilakukan evaluasi terhadap pencapaian customer complaint.

Tabel 4. Key Performance Measurement customer complaint Tahun 2016 


\begin{tabular}{cccl}
\hline Bulan & $\begin{array}{c}\text { Target } \\
\text { (Max.6x/Thn) }\end{array}$ & $\begin{array}{c}\text { Pencapaian } \\
\text { (x/bulan) }\end{array}$ & Penjelasan \\
\hline Jan & $0.5 / \mathrm{bln}$ & 2 & $V R C$ \\
Feb & $0.5 / \mathrm{bln}$ & 1 & $V R C$ \\
Mar & $0.5 / \mathrm{bln}$ & 0 & $N O V R C$ \\
Apr & $0.5 / \mathrm{bln}$ & 6 & $V R C$ \\
Mei & $0.5 / \mathrm{bln}$ & 3 & $V R C$ \\
Jun & $0.5 / \mathrm{bln}$ & 1 & $V R C$ \\
Jul & $0.5 / \mathrm{bln}$ & 1 & $V R C$ \\
Ags & $0.5 / \mathrm{bln}$ & 0 & $N O V R C$ \\
Sep & $0.5 / \mathrm{bln}$ & 0 & $N O V R C$ \\
Okt & $0.5 / \mathrm{bln}$ & 4 & $V R C$ \\
Nov & $0.5 / \mathrm{bln}$ & 1 & $V R C$ \\
Des & $0.5 / \mathrm{bln}$ & 1 & $V R C$ \\
\hline Total & $\mathbf{6}$ & $\mathbf{2 0}$ & \\
\hline
\end{tabular}

\subsection{Tahap Evaluasi dan Analisis}

Setelah melihat hasil dari Key Performance Measurement(PKM)pada setiap poin sasaran terpadu maka manajemen akan melakukan evaluasi. Evaluasi akan dilakukan dengan menentukan penyebab poin sasaran terpadu tidak tercapai, menentukan masalah dan proses perbaikan.Evaluasi akan menyesuaikan data-data yang telah diperoleh sebelumnya.

Tabel 5. Hasil Evaluasi Kabel Tahun 2016

\begin{tabular}{|c|c|c|c|}
\hline No & PKM & $\begin{array}{c}\text { Fault } \\
\text { Categories }\end{array}$ & Cause \\
\hline \multirow[t]{3}{*}{1} & $\begin{array}{l}\text { First Pass } \\
\text { Yield }\end{array}$ & $\begin{aligned} \sim & \text { Low } \\
& \text { Insulation } \\
& \text { Resistance }\end{aligned}$ & $\begin{array}{l}\text { Ketebalan insul tidak } \\
\text { memenuhi spec } \\
\text { minimum (Insulasi } \\
\text { tipis). Diameter } \\
\text { konduktor lebih besar } \\
\text { dari spec. }\end{array}$ \\
\hline & & $\begin{array}{l}\sim \text { High } \\
\text { Conductor } \\
\text { Resistance }\end{array}$ & $\begin{array}{l}\text { Suhu konduktor/kabel } \\
\text { pada saat pengujian } \\
\text { dalam keadaan panas. } \\
\text { Adanya cacat pada } \\
\text { bagian outer sheat. } \\
\text { Penandaan jenis kabel } \\
\text { dan panjang kabel } \\
\text { tidak sesuai }\end{array}$ \\
\hline & & $\begin{array}{l}\sim \text { Visual/kons } \\
\text { truksi }\end{array}$ & $\begin{array}{l}\text { Ketidaksesuaian } \\
\text { konstruksi kabel } \\
\text { maupun material } \\
\text { kabel }\end{array}$ \\
\hline 2. & $\begin{array}{l}\text { Customer } \\
\text { complaint }\end{array}$ & $\begin{aligned} \sim & \text { Non } \\
& \text { Standar } \\
& \text { Length }\end{aligned}$ & Panjang kabel kurang \\
\hline
\end{tabular}

diagram untuk mencari akar permasalahan dari standar kualitas yang belum tercapai oleh PT X. Analisis cause and effect digram menggunakan Fishbone Diagram yang dapat dilihat pada Gambar 3.

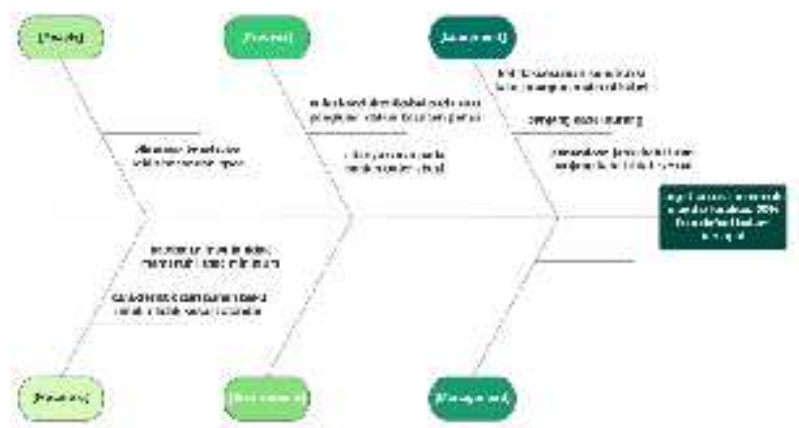

Gambar 3. Fishbone Diagram Analysis

Berdasarkan analisis fishbone diagram maka usulan perbaikan yang ditawarkan untuk melakukan continue improvement dan mencapai standar kualitas yang telah ditetapkan dapat dilihat pada tabel 6 .

Tabel 6. Usulan Perbaikan

\begin{tabular}{|c|c|c|c|}
\hline No & Faktor & Masalah & Improvement \\
\hline 1. & Manusia & $\begin{array}{l}\text { - Ketidaksesuaian } \\
\text { prosedur kerja } \\
\text { yang dilakukan } \\
\text { oleh pekerja } \\
\text { dapat } \\
\text { mengakibatkan } \\
\text { produk cacat. } \\
\text {-Pekerja yang } \\
\text { kurang teliti } \\
\text { juga dapat } \\
\text { mempengaruhi } \\
\text { kualitas produk } \\
\text { dan } \\
\text { menghambat } \\
\text { proses produksi }\end{array}$ & 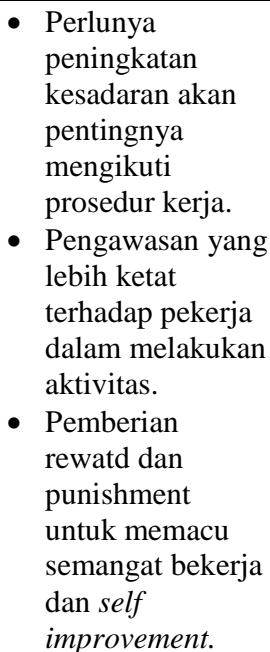 \\
\hline 2. & Material & $\begin{array}{l}\text { - Kualitas yang } \\
\text { tidak sesuai } \\
\text { dengan standar } \\
\text { mengakibatkan } \\
\text { terhambatnya } \\
\text { proses produksi } \\
\text { serta } \\
\text { mempengaruhi } \\
\text { kualitas produk. }\end{array}$ & $\begin{array}{l}\text { - Perlu dilakukan } \\
\text { kontrol yang } \\
\text { lebih ketat agar } \\
\text { material yang } \\
\text { digunakan sesuai } \\
\text { standar. } \\
\text { - Adanya standar } \\
\text { dalam } \\
\text { penyeleksian } \\
\text { supplier. }\end{array}$ \\
\hline 3. & Process & $\begin{array}{c}\text {-Instruksi kerja } \\
\text { yang tidak } \\
\text { dijalankan }\end{array}$ & $\begin{array}{l}\text { Memberikan } \\
\text { arahan-arahan } \\
\text { dalam }\end{array}$ \\
\hline
\end{tabular}




\begin{tabular}{|c|c|c|}
\hline \multicolumn{3}{|c|}{ JURNAL SAINS TERAPAN VOL 4 No. 2, OKTOBER 2018} \\
\hline Equipment & $\begin{array}{l}\text { dengan baik } \\
\text { akan berakibat } \\
\text { cacat pada } \\
\text { material dan } \\
\text { bahkan bisa } \\
\text { menimbulkan } \\
\text { kecelakaan } \\
\text { kerja. } \\
\text { - Kurangnya } \\
\text { kesadaran untuk } \\
\text { melakukan } \\
\text { kalibrasi alat } \\
\text { mengakibatkan } \\
\text { ukuran yang } \\
\text { tidak presisi. } \\
\text { - Kurangnya } \\
\text { kesadaran } \\
\text { operator untuk } \\
\text { memastikan } \\
\text { mesin/alat yang } \\
\text { digunakan } \\
\text { sudah dalam } \\
\text { posisi yang } \\
\text { tepat. }\end{array}$ & $\begin{array}{l}\text { - Kalibrasi alat } \\
\text { counter meter } \\
\text { pada mesin } \\
\text { produksi. } \\
\text { - memperbaiki alat } \\
\text { jetprint }\end{array}$ \\
\hline
\end{tabular}

\section{Kesimpulan}

Berdasarkan hasil perhitungan diperoleh nilai rata-rata metode Key Performance Measurement pada First Pass Yield 94,2 \% dimana PT X menargetkan tingkat produk yang free defect sebesar 99\% serta Customer Complaint mencapai 20 kali dalam setahun.
PT X menargetkan maksimum komplain sebanyak 6 kali setahun. Hal ini menandakan PT $X$ belum bisa mencapai standar kualitas yang telah mereka tetapkan. Beberapa faktor yang penyebab tidak tercapainya standar kualitas tersebut adalah manusia (pekerja), alat/mesin yang digunakan, proses kerja, dan material.

\section{Saran}

Penelitian lebih lanjut dapat menganalisis hubungan antara pengendalian kualitas dengan konsekuensi biaya yang harus ditanggung oleh perusahaan.

\section{Daftar Pustaka}

[1] A. Ahyar, Pengendalian Produksi, Buku 2, Yogyakarta: BPFE,2011

[2] A. V. Feigenbaum, Kendali Kualitas Terpadu, Jakarta: Erlangga, 1992

[3] Ratnadi, E. Suprianto "Pengendalian Kualitas Produksi Menggunakan Alat Bantu Statistik (Seven Tools) Dalam Upaya Menekan Tingkat Kerusakan Produk," in Jurnal Unnur, vol.6, no.2 Juni 2016.

[4] S. Assauri, Manajemen Produksi dan Operasi,Jakarta: LPFE UI, 1993.

[5] S. Reksohadiprodjo, I. Gitosudarmo, Manajemen Produksi, Edisi ke-4, cetakan ke-11 (sebelas), Yogyakarta: BPFE, 2000. 